\title{
The Exploration of the Police Revolution Based on the Principle of Modern Management
}

\author{
Chao LI* \\ Liaoning Anshan Bureau of public security, Anshan, Liaoning, China \\ 334816798@qq.com \\ ${ }^{*}$ Corresponding author
}

Keywords: Policing revolution, Reform of public security, Policing administration.

\begin{abstract}
Police revolution also known as Policing Reform which means the important strategic and epochal reform in the police history of the human beings. Total four times of Police Revolution happened throughout world police history which were the Metropolitan police in London, American police specialization movement, Police modernization in Europe and the United States and Community policing reform model. But the segmentation management method based on "community" has been unable to meet the requirements of "fusion, commonness and cooperation" with the advent of the "big data era". Especially it is very easy to be caused lagging police effectiveness by a fine division of labor and dispersing police allocation in countries with high population density such as China and so on. Therefore, the police reform in the new period is exploring and practicing aiming for the emphasis integrating institutional and power and responsibility combining with the principle of modern management in the paper of mine.
\end{abstract}

\section{Introduction}

The problems including excessive fine division of police duty, police function crossing, dispersing police force resources, police shortage of front-line, more police force, fewer police positions, and fewer promotion opportunities for policemen etc. Are existing in the police operation model today. So the plan " $1+3$ " was put forward by the Ministry of Public Security of the People's Republic of China, deepening the reform of Public Security for them aiming to solving the outstanding contradictions perplexing the public security organ, among the police combating, institutionalizing, bureaucratization and fragmentation. It is proposed exploring the late-model police revolution which combining the "seven-theories" of management on this basis. [1]

\section{The Principle of Management and Reform of Public Security}

\section{System Principle}

The essence of "reform" is the fundamental shift in the aspects of mechanism, system and pattern. Especially, any carelessness happening during the police reform would impact the capacity and level maintaining social stability. Therefore the factors so as the integrity, dynamics, openness, environmental suitability and comprehensiveness etc. The three links of the aim, overall situation and gradation in the plan design should be grasped.

\section{The Principle of the Entirety, Division and Integrity}

The concrete manifestation of the second-time police revolution realized the professionalization of the police. But it was to increase police blindly in the third-time one in which the some negative effects were brought up so from which the fourth-time happened at the end, in which the division of the labor for policemen and the right and liabilities were more clearly. From the above, the result at the fourth-time was bloated organs and inefficient work if "big mixing" is sought blindly. On the contrary, it is possible to result in the both phenomena blocking the way of the cooperation among the policemen' and 
buck-passing because of the excessive division of labor for policemen. How to control the degree combining the similar offices and retaining the uniqueness of the specialized offices, the principle of the entirety division and integration should be depended on. [2]

\section{The Principle of the Right Shift}

No the plans once for all and measures exists, settling a matter at once go for reforming as it is dynamic. Particularly, it is a challenge "to reform" the traditional model that should bring the contradiction between the whole and individual ability and position. Thus the so-called growing pain appears during reform. The principle of right shift should be adopted, so variable can be able to be introduced into "the equation of the reform" by us, after that we can have fine tuning for it until the desired result reaches .

\section{The Principle of Responsibilities}

"Not radius of any rules", it is a necessary means pushing forward work development to implement responsibilities. Hence it is the key to success and failure of the reform how to define the rights and responsibilities and assign work of each link scientifically to different unit and individual during it. At the same time, it is the priority among priorities in the reduction of responsibility system to authorize right with the corresponding supporting system for reward and fine. The proper and modest principle should be followed. Which can't be hypercorrection or weak loose?

\section{The Management of Capability}

It is the quintessence "Making the best possible use of men and material" in the management. Every police constable has the different character ability and growth properties, whose normal development must be influenced if the rigid targets are used for her or his check. So in order to put everyone right into the right post, everyone's willingness should be respected and "the two-way choice" stuck to. Meanwhile the police career planning archive and career system should be built so their specialty can be developed optimally according to them, who work "like a duck to water" and "more with less".

\section{The Principle of Power}

There should be a strong power for management, so as material power mental power and information power as a continuous and effective going for management. Therefore, a successful police reform is not only the change for series, but also needs a matched and sufficient logistical support. Police constable can be able to adapt themselves to the new roles posts and changes.

\section{Exploring and Practicing in New-style of Police Revolution}

\section{Well-design Thinking for Reform}

The modern police mechanism will be built enhancing strike force and reliability according to the principle of efficiency-simplification and unification administration, by means of the policy "two-integration, two adjustment, two-specification and one-reconstruction" to integrate the institutions, police force, adjust the institution-size and number of police posts, confirm the names of the organizations and job function, reconstruct police operation system for realizing "three-change" including changes of system, mechanism and assurance; "three-minus, three-increase" meaning reducing institution, police force and the quantity of leadership positions and increasing the quantity of the local police station and team, police force and leadership positions; organization structuring, police force distribution, the number of police leadership posts all lean to specialty, substations in urban area and local police station. And then the public security bureau of the city will become the nerve center and headquarters leading varieties of the policemen of good fight and more professional; public security sub-bureaus will be built into combat entities, local police station into an independent combat units and the three-dimensional combat system structured. So the powerful force of overall combat can be cohered, intelligence information orientation, dynamic police support, support by police cooperation, featuring professional norms, reflecting the characteristic of real combat and meeting the actual combat requirement. [3] 


\section{Innovating to the Combat Mode}

The mode of " $4+10$ " is built after the reform and eleven institutions in the original public security bureau of the city are integrated to only four institutions which are the police command office, political office, logistics office and supervision office; original twenty-seven police officers are integrated into four sub-bureaus including the national security and counter-terrorism bureau, Criminal investigation bureau, Population and immigration administration and Traffic safety administration and six detachments which are Economic crimes investigation team, Public security administration brigade, Technical investigation brigade, Patrol and swat teams, Prison management team and legal team. The mode of " $4+9+$ local police stations are built in four sub-public bureaus in urban to which subordinate two comprehensive departments including prohibition office and office of political work, Domestic security guard brigade, Criminal investigation brigade, population and immigration management team, Technical investigation brigade, Patrol and swat teams and Legal team, total nine combat department and local public stations. "Three-teams and one-office" in each urban public station which are community team, case team, traffic patrol team and service command office.

\section{Reconstructing and Completing Operating Mechanism}

The "four center" including Public security control center, Law enforcement supervision center, Examination and approval center and Information center are reconstructed by means of resource integration, Dimensional synthesis and Centralized management by specified departments, which completing the integrated intelligence command platform, Synthetic warfare platform, Unified examination and approval platform and Multidimensional data platform promoting business collaboration of business , information and work flows; deeply fusion, dismantling "separating wall "; and getting through "obstruction", so realizing all of police service running through; actively exploring the, police operating mechanism of integration, intensification, high-efficiency; Accelerating formation of core fighting force public security.

\section{Controlling Stably the Pace of Reform}

More than 40 percentage of the original police force in the institutions and offices of the public security bureau of the city will be planned to transfer to lower-offices and teams by means of reform and only 5 percentage of the police force will be in the institutions of the public security bureau of the city after reform. No more than 35 percentage of a variety of police force in the institutions; more than 60 percentage of the police force will be in the urban public security sub-bureaus. More than 35 percentage of police force will be in the local police stations. The "seven-micro-measures" including micro-five-decision, micro-managing, micro-check, micro-easing-burden, micro-linkage, micro-division-work and micro-forbidding will be used to solve the problems for the unscientific, incomplete and hindered problems in terms of organization structuring, cadres of configuration, disposition of police force and operating mechanism; The complete and supporting police management process and check measures will be used for getting through the last kilometer in reform and insuring it to pass smoothly run-in period. [4]

\section{Checking the Result of the New Policing Model}

The public security work efficiency has been greatly improved; public security situation is getting better and better; the crowd gained a clear boost; reform dividend is fermenting continuously. Vitality and fighting capacity is been increased and the masses' sense of gain and satisfaction rate boosted after reform.

\section{Controlling Risk}

Implementing the active police service of "quaternary" including commanding-dispatching, early warning, disposing and striking; it promotes the "information and commanding linkage", "intelligence and logistics joint" integrating institutions from which the factors of social unrest and a variety of potential safety hazard can be discovered earlier, earlier to be solved and then smaller effect. The "1-3-8 disposal of circle" and the construction of "a piece of drawing of police" promoting the dynamization, delay ring, visualization of mobilization of police and assembling of police instructions, so effectively 
shortening emergency response time, increasing emergency disposal rate. The emergency disposing rate has been increased 35 percentage, but controllable events less 24 percentage, the time answering alarm and disposing less 1.5 minutes than before since this year. [5]

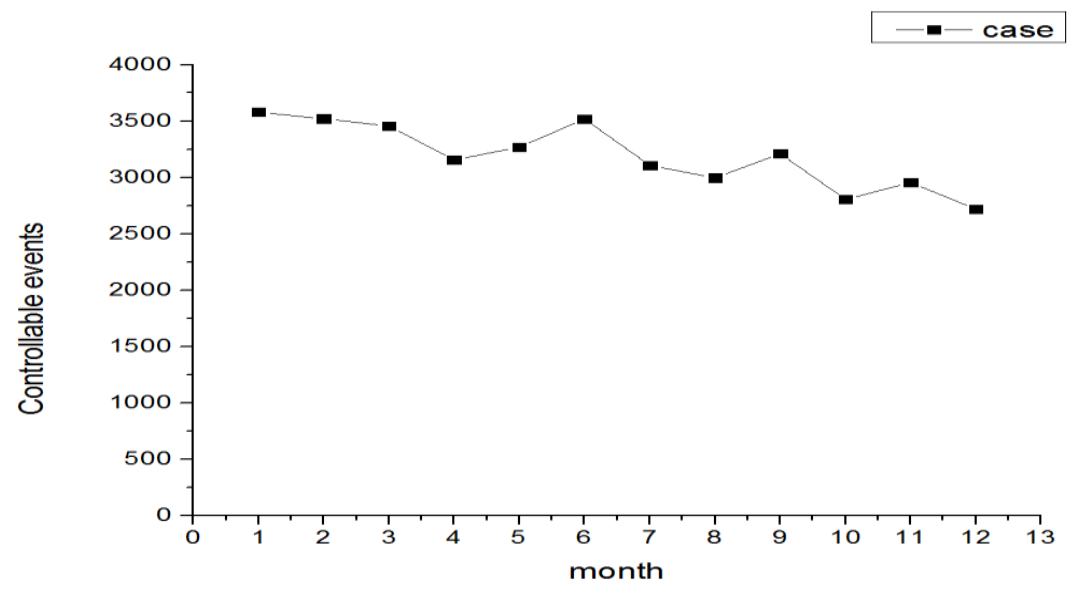

Fig. 1 The number of controllable events

\section{Fighting Criminals}

The detecting and striking is transferring and upgrading to integration of strength, resources and means, from passively meeting criminals' attack to target hitting and realizing scale blow, corps combat and a number of major cases have been successfully solved. The rates of solved criminal cases have increased 44 percentages this year than the same time last year. Eight types of major criminal cases 39 percentage. All homicide cases solved as soon as they happened.

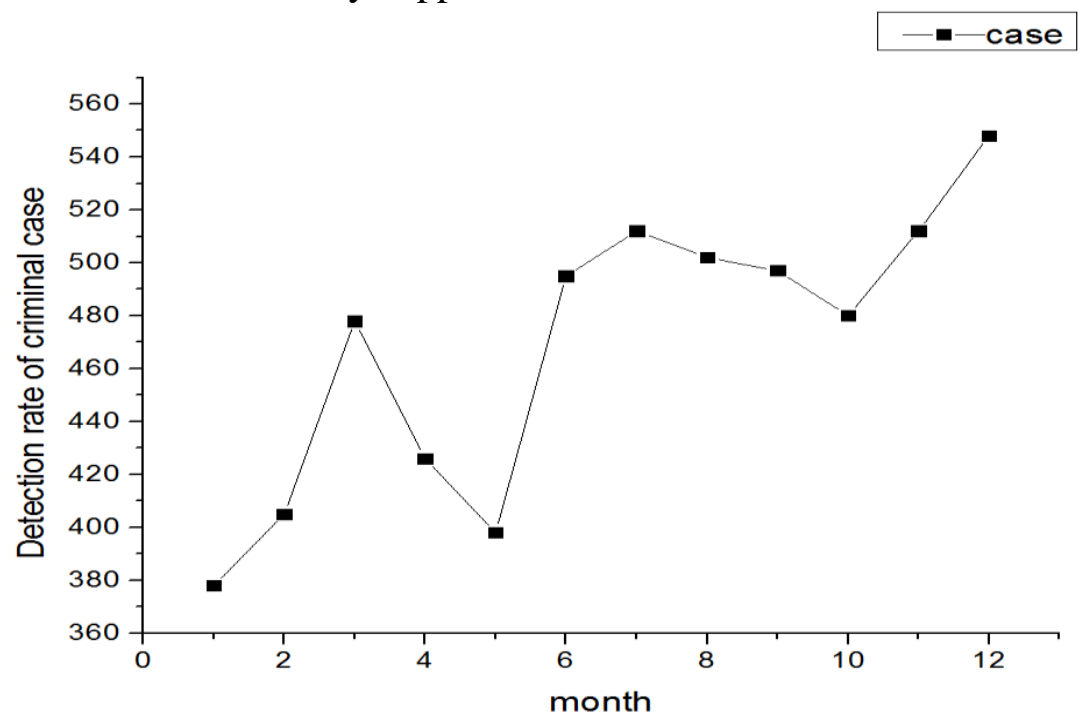

Fig. 2 The detection rate of criminal case

\section{Patrol Guard}

The precautionary measures of the integrated support by coordinated action of united-duty and combined-action of "two+two+two", the regular night-patrol of the police in the office, video-patrol and street patrol etc. Have been executed together, the three-dimensional prevention and control system has been grown up with professionals such as police, auxiliary police and security personnel combining with masses, covering the whole city, realizing "Five-drop" including criminal case, homicide case, public-security case, public security liability accident and mass disturbance; The homicide case rate drops off 13.3 percentages than the same time last year; the accident of traffic and fire down 40 percentages; mass disturbance down 45 percentages which are at recent ten years. 


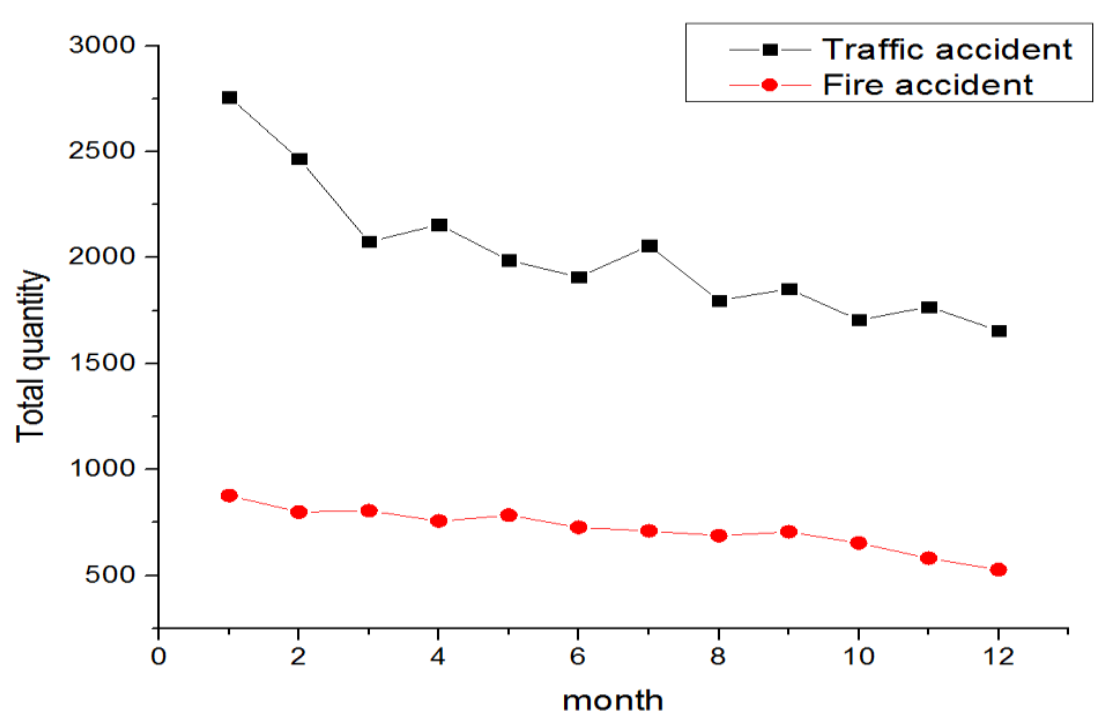

Fig. 3 The number of traffic accident and fire accident

\section{Security Of Society}

The effectiveness of new model for traffic violation punishment is prominent with "three police varieties integration" including the police of community, patrol and special police and traffic police. Daily average Slscene forensics, investigation and penalty for motor vehicles being disorganized over one thousand pieces cases, upping 45 percentage than the same time last year, but the traffic accidents down 42 percentage in the whole city so effectively solving the problems so-called "urban disease " so as traffic jam and difficult driving. [6]

\section{Optimizing Services}

Positive response on what the masses is reflecting, thinking and hopping and strengthening the thinking of "internet police", advocating self-service, dealing with online, making an appointment for your transaction, transaction nearby, executing "fingertip policing", which benefit person-time 2.9 million who enjoying more and easier intimate and personal services. The cases of public security petition and reporting the complaints on police down and satisfaction with the public security up by a large margin in the early five months of this year.

\section{Team Construction}

944 illegal and undisciplined policemen occupying 15.8 percentage of the total police force are investigated and punished in the series of combined blow being played so as clearing up the style and strictly enforcing discipline, standardizing police and flying-supervisors and traversing inspectors. The police team has taken on a new look after these and the problems are solved promotion of non-leading cadres and no corresponding to the rank of police and so on. The "three fire", namely joining the party at front-line, making contributions at front-line and promotion at front-line, so the vitality in the team is inspired further. The proportion of grass-roots police force is up to $61.3 \%$. 


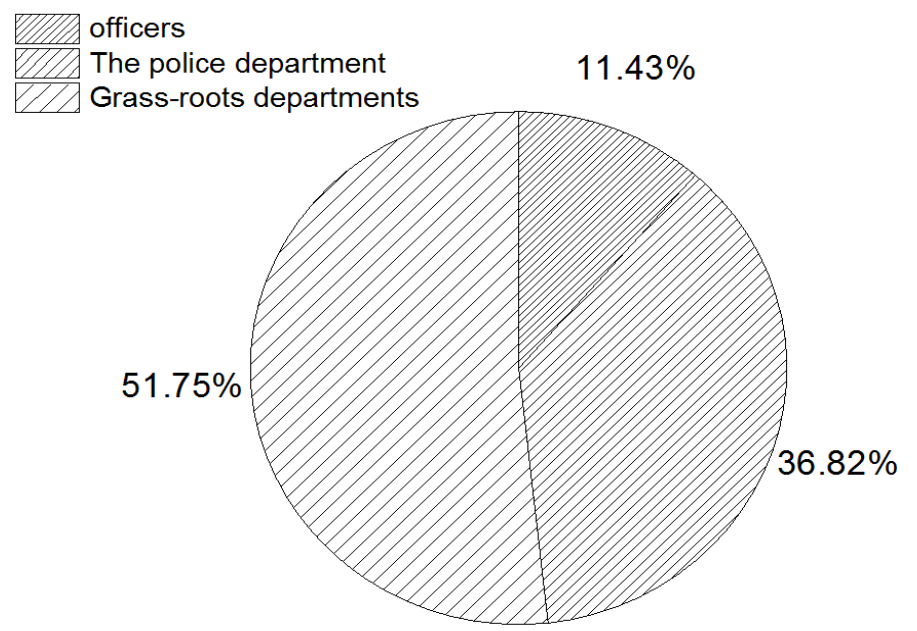

Fig. 4 The Police force structure before Police revolution

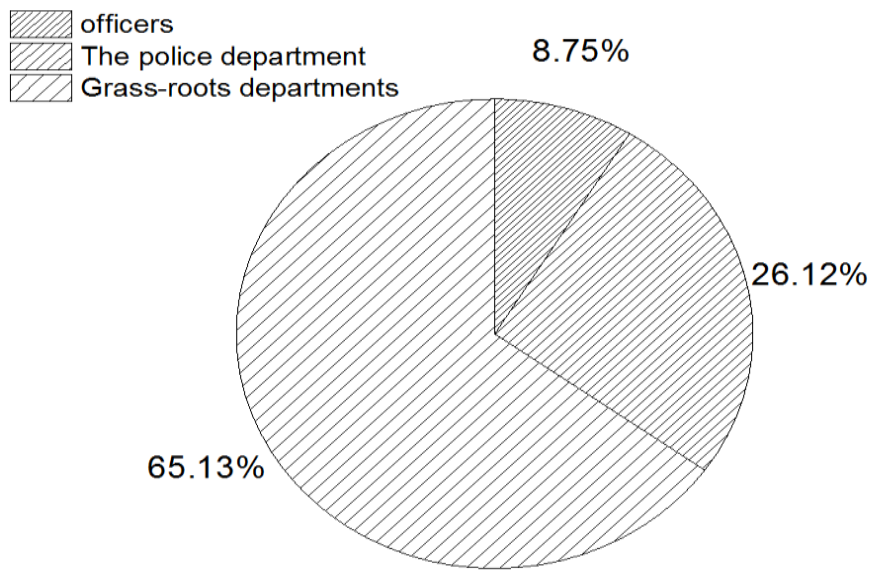

Fig. 5 The Police force structure after Police revolution

\section{References}

[1] Lynda Gratton, “The New Rules of HR Strategy,” HR Focus, 1998, pp.13-14.

[2] Dawei Wang, "The fifth police Revolution: ten on the general trend of World Police Affairs", People's Public Security University of China Press, pp.56-80, 2012(in Chinese).

[3] Linda Davidson, "Measure What You Bring to the Bottom Line," Workforce, September, 1998, pp.34-40.

[4] Dawei Wang, "The principle of Police Science in Europe and America - where does the world police revolution go", People's Public Security University of China Press, 2001, pp.18-23(in Chinese).

[5] Rick Garnitz, “Aging Workforce Poses an HR challenge,” ACA News, March 1999, pp. 20-21.

[6] Bruce R. Ellig, "Is the Human Re-source Function Neglecting the employees?" Human Resources Management, Springer, 1997, pp.91-95. 